\title{
Twist and Shout: One Decade of Meta-Analyses of Erythropoiesis-Stimulating Agents in Cancer Patients
}

\author{
Julia Bohlius ${ }^{\mathrm{a}}$ Thomy Tonia ${ }^{\mathrm{a}}$ Guido Schwarzer $^{\mathrm{b}}$ \\ anstitute of Social and Preventive Medicine, University of Bern, Bern, Switzerland; ${ }^{\mathrm{b}}$ Institute of Medical Biometry \\ and Medical Informatics, Freiburg, Germany
}

\section{Key Words}

Cancer-related anemia - Epoetin •

Erythropoiesis-stimulating agents $\cdot$ Hemoglobin .

Red blood cell transfusion $\cdot$ Thromboembolic events

\begin{abstract}
Anemia associated with cancer and cancer therapy is a common and important issue in the treatment of patients with malignant disease. Conventionally, blood transfusions are used to treat severe cancer-related anemia. Short- and longacting preparations of recombinant human erythropoiesisstimulating agents (ESAs) offer an alternative treatment option. Multiple studies and subsequent meta-analyses have demonstrated that ESA treatment increases hemoglobin levels and reduces the likelihood of transfusion for a proportion of treated patients. However, studies that attempted to evaluate whether ESAs improve tumor response and survival have generated conflicting evidence. Results of smaller trials reporting improved survival outcomes were contradicted by large randomized controlled trials that reported more deaths in patients receiving ESAs. In addition, there is strong evidence that cancer patients receiving ESAs have an increased risk of thromboembolic and cardiovascular events. We herein review the main meta-analyses published in the field, their strengths and weaknesses, their contribution to patient management and future perspectives for systematic reviews.
\end{abstract}

Copyright ๑ 2010 S. Karger AG, Basel

\section{KARGER}

Fax +4161306 1234

E-Mail karger@karger.ch

www.karger.com (c) 2010 S. Karger AG, Basel

$0001-5792 / 11 / 1252-0055 \$ 38.00 / 0$

Accessible online at:

www.karger.com/aha

\section{Introduction}

Anemia, defined as a deficiency in the concentration of hemoglobin ( $\mathrm{Hb}$ )-containing red blood cells (RBCs), is a widely prevalent complication among cancer patients. About $32 \%$ of patients present with anemia at diagnosis and about $54 \%$ of initially non-anemic cancer patients develop anemia during treatment $[1,2]$. Anemia is caused by either the cancer itself or by cytotoxic treatment [3]. For affected patients, anemia can be a debilitating problem; it negatively influences their quality of life (QoL) [4] and is associated with shorter overall survival [5]. Homologous blood transfusion is the fastest method to alleviate symptoms caused by anemia; however, short- and long-term risks such as transmission of infectious diseases, transfusion reactions and alloimmunization have to be faced [6]. Short- and long-acting preparations of recombinant human erythropoiesis-stimulating agents (ESAs) offer an alternative treatment option, reducing the risk for infections and adverse events associated with RBC transfusions.

Mainly three different recombinant erythropoietins are available to date: epoetin $\alpha$ (Procrit $^{\circledR}$, Johnson \& Johnson; Epogen ${ }^{\circledR}$, Amgen), epoetin $\beta$ (NeoRecormon ${ }^{\circledR}$, Roche) and darbepoetin $\alpha$ (Aranesp ${ }^{\circledR}$, Amgen). Epoetins $\alpha$ and $\beta$ consist of 165 amino acids, but they differ in their carbohydrate content. Darbepoetin has a longer half-life 
compared to epoetin $\alpha$ and $\beta$. The three erythropoetins have similar clinical efficacy $[7,8]$ and are considered as members of the same pharmacologic class [9]. Other novel molecules, i.e. the continuous erythropoietin receptor activator $[10,11]$ and biosimilars, including epoetin $\alpha$, epoetin $\zeta$ and epoetin $\delta$, have been developed. Currently, epoetin $\zeta$ is approved for the treatment of chemotherapyinduced anemia in patients with solid tumors, malignant lymphoma and multiple myeloma $[12,13]$.

Since ESAs were licensed for the treatment of anemia in cancer patients in 1993, more than 80 randomized controlled trials (RCTs) on the effects of ESAs versus control were conducted in cancer patients. In order to systematically organize these studies, several systematic reviews and meta-analyses were done. The first meta-analysis was published in 1997 [14]. Ever since, more than 20 meta-analyses and systematic reviews on the effects of ESAs in cancer patients have been published. We here discuss the main meta-analyses published in the field, their strengths and weaknesses, their contribution to patient management and future perspectives for systematic reviews in this field. These issues will be structured by selected clinical outcomes, i.e. RBC transfusions (RBCTs), thromboembolic events and survival. Systematic reviews and meta-analyses restricted to specific patient populations, i.e. patients with myelodysplastic syndrome [16, 17], head-and-neck cancer [18] or specific outcomes, i.e. hematological response [15] or QoL [19, 20], will not be reviewed here.

\section{Red Blood Cell Transfusions}

ESAs efficiently increase $\mathrm{Hb}$ levels in cancer patients and reduce need for RBCTs. Up to now, more than 60 RCTs evaluated the risk for transfusion in patients receiving ESAs compared to controls. The benefit of ESAs in terms of reduced risk for RBCTs was shown in the majority of randomized trials, and most of these trials were sufficiently powered to detect statistically significant differences between experimental and control arms. Besides, RBCT risk was evaluated in eleven meta-analyses $[14,21-$ 30]. One of the first meta-analyses was commissioned by the Agency for Health Research and Quality and published by Seidenfeld et al. [21] in 2001. This analysis was updated in a collaborative effort with the Cochrane Hematological Malignancies Group in 2002 [22]. In 2004/ 2005 , these analyses were updated together with investigators from the University of Birmingham [23] and the Agency for Health Research and Quality [25]. Apart from this collaboration, several other meta-analyses reported results for RBCTs [14, 26-30].

All meta-analyses demonstrated that ESAs reduce the risk for transfusions in a statistically and clinically meaningful way. Results of these meta-analyses are shown in the upper part of figure 1. At first glance, the results reported by Seidenfeld et al. [21] and by Ross et al. [27] are strikingly different from the other results. However, in these meta-analyses the odds ratio (OR) was used as effect measure whereas the risk ratio (RR) was used in the others. It is well known that $\mathrm{OR}$ and $\mathrm{RR}$ values can be very different if events are common [31]. RBCT is a very common event in cancer patients. Accordingly, results for meta-analyses using OR as summary measure show very different results. A re-analysis of Bohlius et al. [32] in 2006 using OR is shown in the lower part of figure 1. Their OR (0.43) is very similar to those reported by Seidenfeld et al. [21] (OR 0.38) and Ross et al. [27] (OR 0.44). All nine meta-analyses using $\mathrm{RR}$ as effect measure report very similar results ( $\mathrm{RR}$ range $0.58-0.67$ ).

However, most meta-analyses on RBCTs show some or even substantial heterogeneity. This indicates variation between trials that cannot be explained by chance. To explore this heterogeneity, several working groups conducted meta-regression analysis. For example in a multivariate stepwise meta-regression analysis, Bohlius et al. $[24,32]$ revealed that ESA effect size was influenced by the type of underlying malignancy and source of data. Unpublished data show more conservative results than data taken from full-text or abstract publications. Furthermore, in patients with hematological malignancies and myelodysplastic syndrome, the effect was similar, whereas the treatment effect was markedly different in patients with solid tumors. In summary, meta-regression analysis within a meta-analysis may help to identify factors that modify effect sizes and that may help to explain different effect sizes observed between different trials.

To avoid the perils of publication bias, additional unpublished or unreported data were requested from the clinical trial investigators and included in the meta-analysis published by Bohlius et al. [22]. Including these additional unreported data in the analysis generated a more conservative estimate. Thus, meta-analysis including unreported data may help to achieve more realistic estimates of the effectiveness of drugs.

Despite efforts to include unreported data in RBCT meta-analyses, some indication for publication bias still exists as tests for funnel plot asymmetry are significant in some meta-analyses. For example, a re-analysis of the 


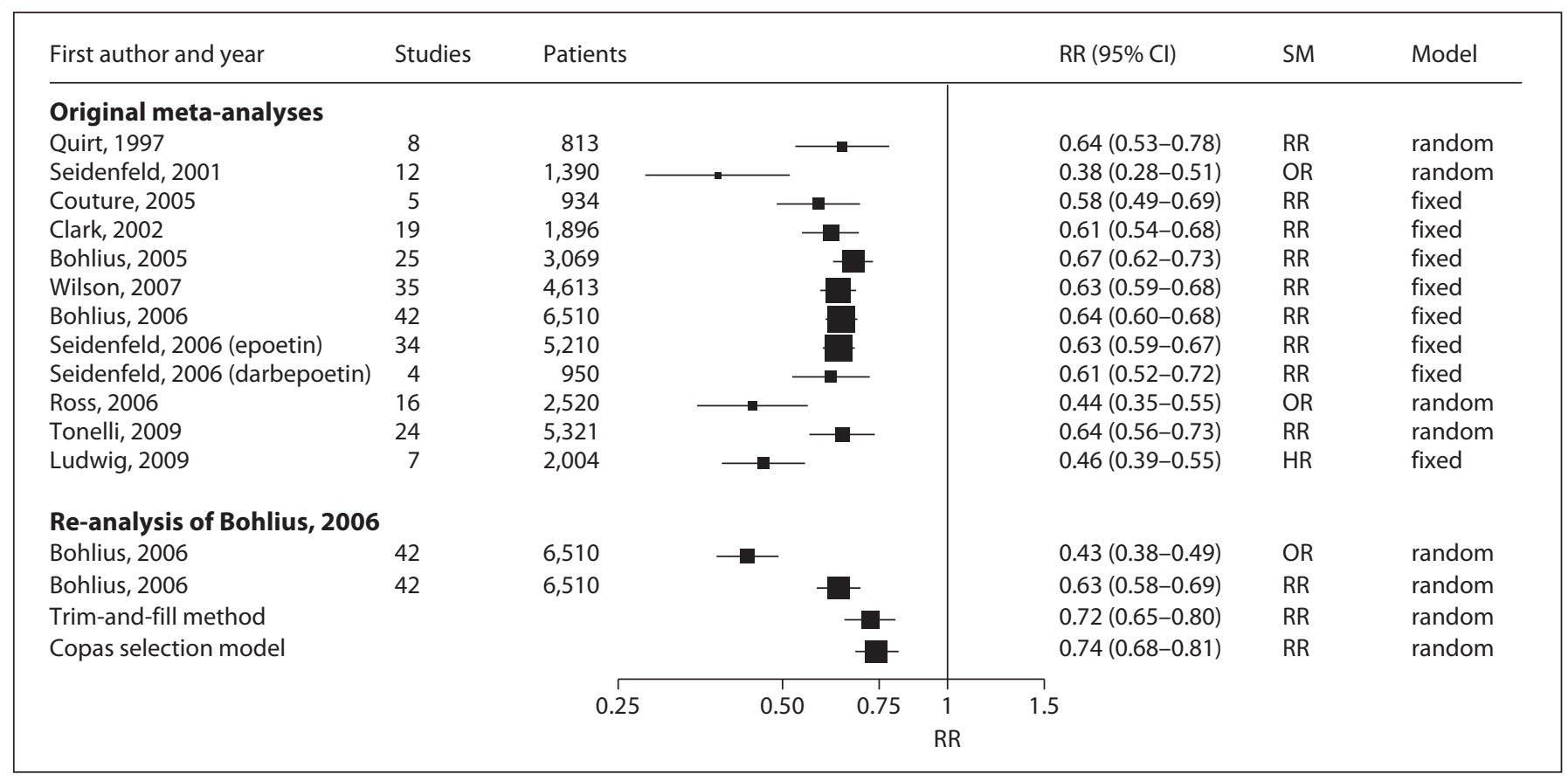

Fig. 1. Forest plot of meta-analyses on the effects of ESAs on the risk of RBCTs. Columns report on the total numbers of studies in meta-analysis (Studies) and participants (Patients); on effect measure (RR) and its 95\% CIs; summary measures used in meta-analysis (SM), and the meta-analysis model (Model: fixed and random effect models).

Fig. 2. Funnel plot of studies on RBCTs included in the Cochrane review by Bohlius et al. [32]. a Original analysis. b Result of the trim-and-fill method applied to adjust for publication bias.

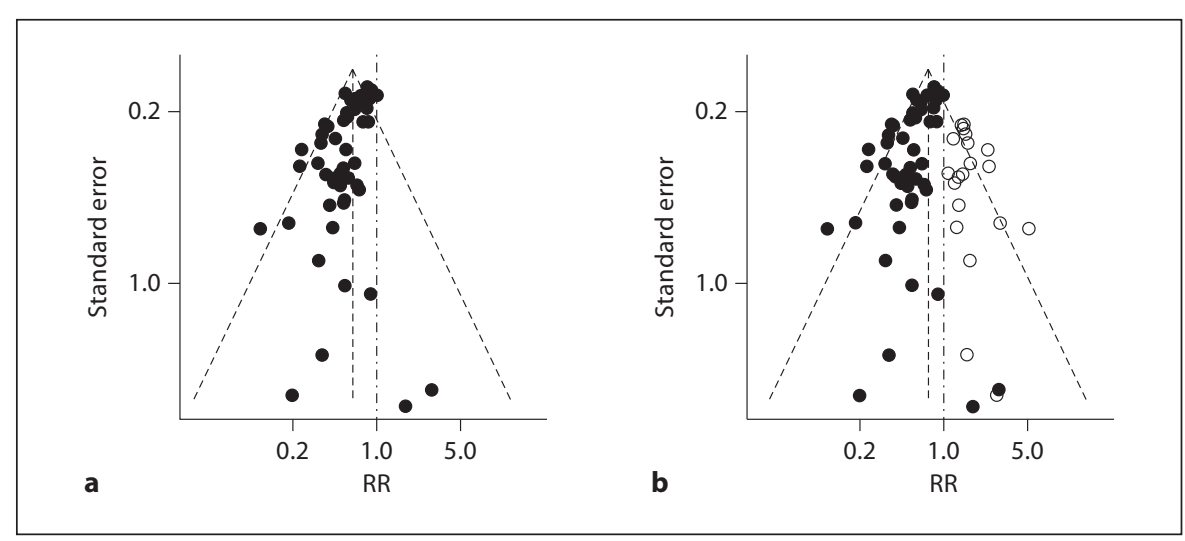

data of Bohlius et al. [32] using the test proposed by Harbord et al. [33] revealed a significant difference $(p=0.039)$. The funnel plot of these data is shown in figure 2a. Statistical methods to adjust for potential publication bias have been developed during the last decade. In this paper, we apply two prominent adjustment methods, the trimand-fill method [34] and the Copas selection model [35], to the data from Bohlius et al. [32] as a kind of sensitivity analysis. The results for these two adjustment methods are given in the lower part of figure 1; the result for the trim-and-fill method is also shown in figure $2 \mathrm{a}$. Both methods suggest that the effect estimate - adjusted for potential publication bias - is slightly smaller, i.e. closer to the null effect, but still highly statistically significant: OR 0.72 (trim-and-fill method) and OR 0.74 (Copas selection model). 


\begin{tabular}{|c|c|c|c|c|c|c|}
\hline First author and year & Studies & Patients & & $\mathrm{RR}(95 \% \mathrm{Cl})$ & SM & Model \\
\hline \multicolumn{7}{|l|}{ Original meta-analyses } \\
\hline Bohlius, 2005 & 12 & 1,738 & & $1.58(0.94-2.66)$ & $\mathrm{RR}$ & fixed \\
\hline Bohlius, 2006 & 35 & 6,769 & $-\square$ & $1.67(1.35-2.06)$ & $\mathrm{RR}$ & fixed \\
\hline Seidenfeld, 2006 (epoetin) & 30 & 6,092 & $\bar{n}$ & $1.69(1.36-2.10)$ & $\mathrm{RR}$ & fixed \\
\hline Seidenfeld, 2006 (darbepoetin) & 1 & 314 & & $1.44(0.47-4.42)$ & $\mathrm{RR}$ & \\
\hline Ross, 2006 & 11 & 2,029 & - & $1.41(0.92-2.17)$ & OR & random \\
\hline Bennet, 2008 & 38 & 8,172 & & $1.57(1.31-1.88)$ & $\mathrm{RR}$ & random \\
\hline Ludwig, 2009 & 7 & 2,122 & $\longrightarrow$ & $1.57(1.10-2.25)$ & $\mathrm{HR}$ & fixed \\
\hline Aapro, 2008 & 12 & 2,297 & $\longrightarrow$ & $1.62(1.13-2.32)$ & $\mathrm{HR}$ & fixed \\
\hline Tonelli, 2009 & 13 & 3,420 & $\square$ & $1.69(1.27-2.24)$ & $\mathrm{RR}$ & random \\
\hline Glaspy, 2010 & 44 & 13,196 & & $1.48(1.28-1.72)$ & OR & random \\
\hline \multicolumn{7}{|l|}{ Re-analysis of Bohlius, 2006} \\
\hline Bohlius, 2006 & 35 & 6,769 & $\longrightarrow$ & $1.63(1.28-2.07)$ & OR & random \\
\hline Bohlius, 2006 & 35 & 6,769 & -1 & $1.52(1.22-1.89)$ & $\mathrm{RR}$ & random \\
\hline Trim-and-fill method & & & $-\mathbf{n}$ & $1.31(1.06-1.62)$ & $\mathrm{RR}$ & random \\
\hline \multirow[t]{3}{*}{ Copas selection model } & & & -1 & $1.36(1.09-1.70)$ & $\mathrm{RR}$ & random \\
\hline & & 0.5 & $\begin{array}{l}1 \\
2\end{array}$ & $\overrightarrow{5}$ & & \\
\hline & & & R & & & \\
\hline
\end{tabular}

Fig. 3. Forest plot of meta-analyses on the effects of ESAs on the risk of thromboembolic events. Columns report on the total numbers of studies in meta-analysis (Studies) and participants (Patients); on effect measure (RR) and its 95\% CIs; summary measures used in meta-analysis (SM), and the meta-analysis model (Model: fixed and random effect models).

In conclusion, various meta-analyses have fairly consistently shown that the use of ESAs effectively reduces the RBCT risk. Inclusion of unreported data helped to generate a more conservative estimate. However, under constrained resources, efforts to obtain unreported data will most often only be an exception rather than a rule. Resource constraints apply to both investigators conducting the meta-analyses as well as clinical trial investigators who are requested to provide unreported data. Statistical adjustment methods can be useful to evaluate the sensitivity of results to potential publication bias.

\section{Thrombovascular Events}

ESAs have the potential to increase thombogenic activity either by augmented $\mathrm{Hb}$ levels or other mechanisms. Healthy volunteers receiving recombinant ESAs demonstrate increased platelet reactivity and endothelial activation [36]. In general, cancer patients are at increased risk to develop thrombovascular events (TVEs); nevertheless it is a rare event. Therefore, a large sample size is needed to achieve sufficient power to detect differences between ESA and control groups if they exist. None of the individual RCTs conducted to date was designed or powered to detect an increased risk for TVEs. In most studies, TVEs were evaluated as part of the general safety and adverse event assessment only. Today, data for thromboembolic events are available from about 50 RCTs comparing ESA with no ESA treatment in cancer patients. Although the majority of these studies showed an increased risk for thromboembolic events in ESA patients compared to controls, most studies failed to achieve conventional levels of statistical significance. In this situation, a metaanalysis may increase the statistical power and thus prevent undue delays in the detection of beneficial or harmful effects of medical treatments [37].

TVEs were evaluated in nine meta-analyses [22, 24-27, 30, 38-40] (fig. 3). The first meta-analysis that evaluated TVEs was based on 12 studies including 1,738 patients [22]. The overall estimate for RR to develop TVEs was increased by a factor of 1.58 (95\% CI 0.94-2.66) for ESA-treated patients compared to controls [22]. However, the observed effect did not reach conventional levels of statistical significance. When this meta-analysis was updated in 2006, data from a total of 35 studies and 6,679 patients were analyzed [24]. In this updated analysis, the previously observed effect size was confirmed and statistical signifi- 
Fig. 4. Funnel plot of studies on thromboembolic events included in the Cochrane review by Bohlius et al. [32]. a Original analysis. b Result of the trim-and-fill method applied to adjust for publication bias.

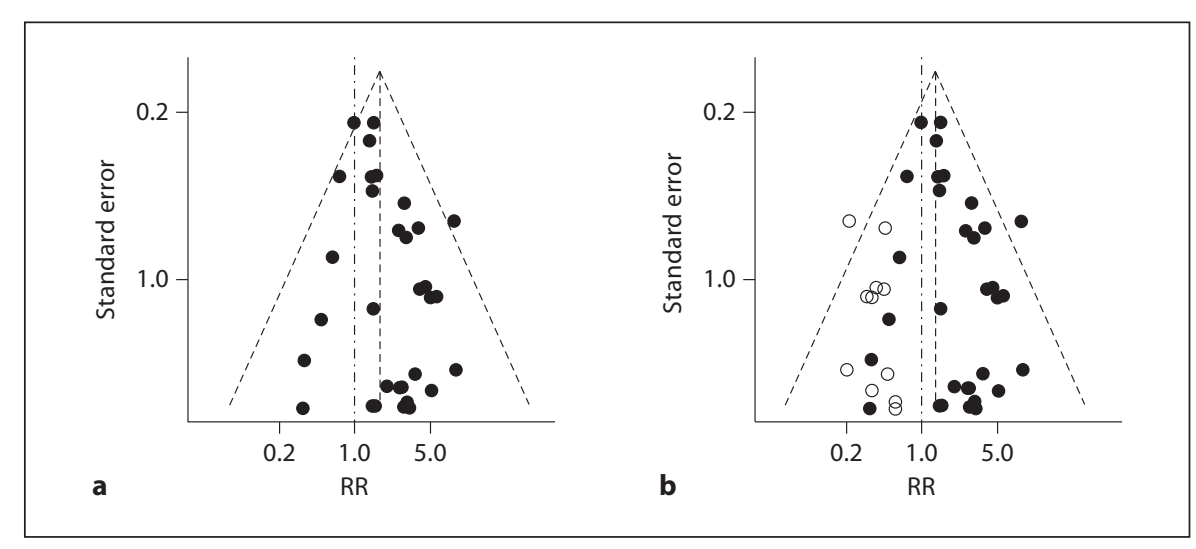

cance was reached (RR 1.67, 95\% CI 1.35-2.06) [24]. All but one [27] subsequent meta-analyses confirmed the observed highly statistically significant effect. This example emphasizes the advantage of meta-analysis to increase statistical power by pooling across several (small) studies. In addition, it illustrates that meta-analyses may help to inform patients, physicians and decision-makers in a more timely manner; an increased risk for thromboembolic events was demonstrated in cancer patients receiving ESAs and published in a medical journal in 2006 based on a meta-analysis [24]. In contrast, the first RCTs showing statistically significant differences between ESA and control treatment were published in medical journals in 2008 [41, 42].

Main limitations of these literature-based meta-analyses are potential biases, e.g. outcome reporting and publication bias. Authors may highlight an increased risk of TVEs in ESA patients compared to controls but may be reluctant to report this if the opposite effect is observed, i.e. TVEs observed less frequently in the ESA group compared to controls [43]. The published literature may therefore represent a biased sample. A funnel plot for the data from Bohlius et al. [32] given in figure 4a suggests that negative results (in this case no thrombotic event) have been underreported [32]. Accordingly, the Harbord test for funnel plot asymmetry [33] is significant with $\mathrm{p}=$ 0.021 . A sensitivity analysis to evaluate the impact of biases using the trim-and-fill method [34] and the Copas selection model [35] results in smaller but still statistically significant effect estimates (lower part of fig. 3, fig. 4b).

The concern of reporting biases may be less of an issue in meta-analyses of individual-patient data (IPD). Data for this type of meta-analyses are taken directly from published and unpublished RCTs and not from publications or reports, thus, publication or reporting biases are less likely to occur. For ESAs, TVEs were evaluated in two IPD meta-analyses [30, 39]. Both meta-analyses were restricted to selected ESA products. Epoetin $\beta$ was evaluated in seven trials including 2,112 patients in one metaanalysis [39] and darbepoetin in 12 trials including 2,297 patients in the other meta-analysis [30]. RR for TVEs was increased (RR 1.57, 95\% CI 1.10-2.26 [30], and RR 1.62, 95\% CI 1.13-2.31 [39]). Thus, these IPD meta-analyses confirm the findings from previous literature-based meta-analyses.

Nevertheless, another source of bias, i.e. detection bias, cannot be excluded. None of the RCTs evaluating ESA therapy in cancer patients investigated systematically TVEs including a prospective definition for TVEs and standardized screening and diagnostic procedures. Physicians treating cancer patients with ESAs might be more observant towards TVEs in patients receiving ESAs compared to controls. Therefore, a risk for detection bias is inherent in each individual RCT included in the various meta-analyses. Since the quality of a meta-analysis is limited by the quality of the original studies, the quality of the primarily conducted RCTs remains the Achilles' heel of any meta-analysis.

\section{Survival and Mortality}

Researchers have also hypothesized that strategies to diminish cancer-related anemia might alleviate not only anemia-related symptoms and improve QoL but also improve tumor response and possibly extend overall survival. This line of argument was mainly based on evidence from in vitro and animal model studies indicating that anemia, with the consequence of increased tumor hypoxia, might result in a poorer response to radiother- 


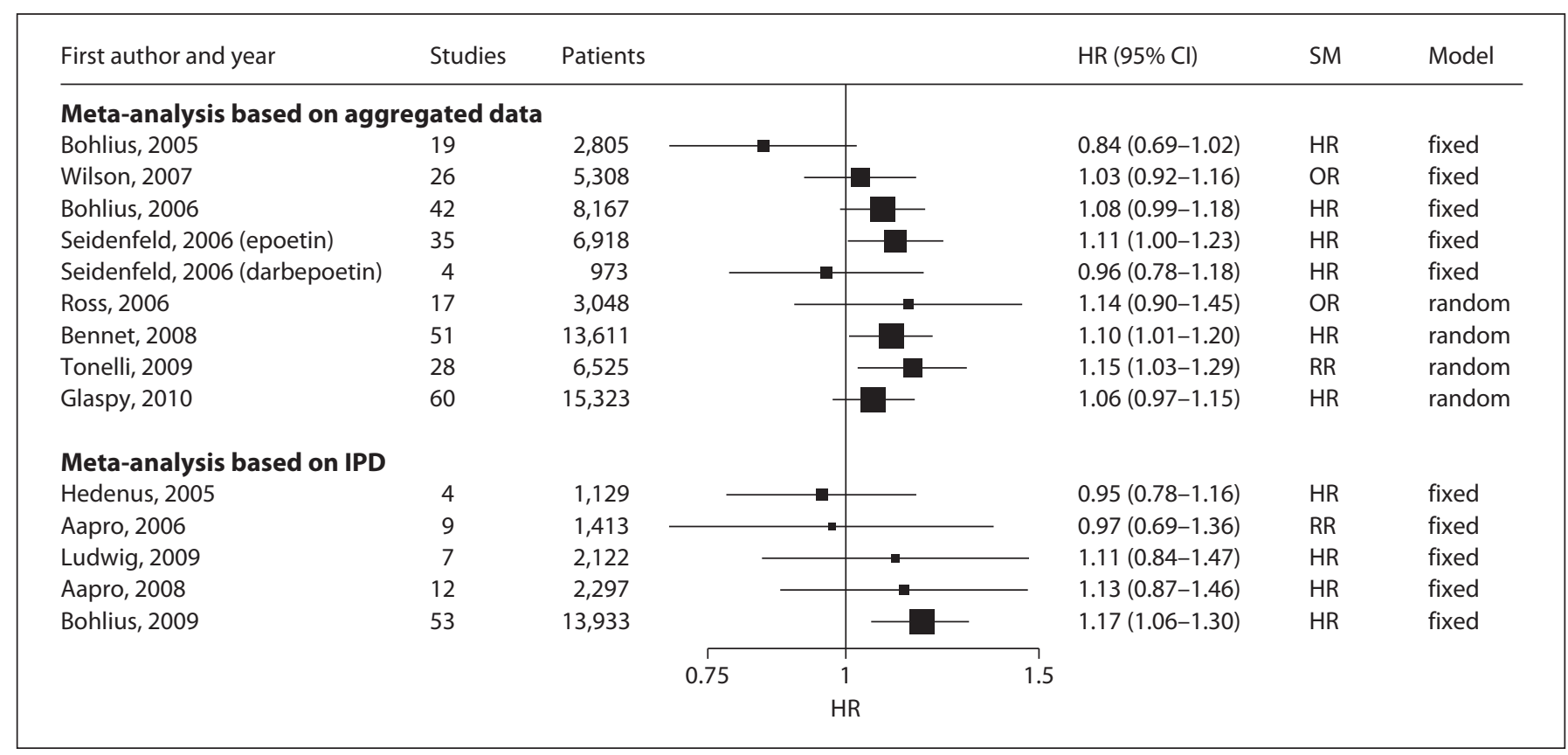

Fig. 5. Forest plot of meta-analyses on the effects of ESAs on the mortality risk. Columns report on the total numbers of studies in meta-analysis (Studies) and participants (Patients); on effect measure (HR) and its 95\% CIs; summary measures used in meta-analysis (SM), and the meta-analysis model (Model: fixed and random effect models).

apy or oxygen-dependent chemotherapy $[44,45]$. Strategies to improve tumor oxygenation could thus potentially improve tumor control and survival [46-50]. However, RCTs that have attempted to evaluate whether ESAs improve tumor response and survival have generated conflicting evidence. An early study, not primarily designed to evaluate survival and tumor progression, showed improved survival outcomes [51]. This study was in contrast to large RCTs that reported more deaths in ESA patients compared to controls in various clinical settings, i.e. patients with head-and-neck cancers undergoing radiotherapy $[52,53]$, patients with metastatic breast cancer undergoing chemotherapy $[54,55]$ and patients with advanced-stage cancers not receiving chemotherapy [56]. These conflicting data prompted three Oncologic Drug Advisory Committee hearings of the Federal Drug Administration in 2004, 2007 and 2008 where the safety of ESAs was discussed $[9,57,58]$. Several restrictions to ESAs were implemented following these hearings.

Several systematic reviews and meta-analyses had attempted to evaluate survival and mortality. The majority of these meta-analyses were based on aggregated data published in the literature. The first literature-based sur- vival analysis, supplemented with unpublished data, was published in 2005 by Bohlius et al. [22]. Another seven literature-based meta-analyses were published during the following years [23-27, 38, 40].

Intriguingly, the results of these meta-analyses changed over time (fig. 5, upper part). The first meta-analysis addressing survival [22] showed an overall survival benefit for ESA patients: unadjusted hazard risks (HRs) of 0.84 (95\% CI 0.69-1.02) and 0.81 (95\% CI 0.67-0.99) when including adjusted results for single studies. These results were contradicted by later meta-analyses showing effect estimates of 1.08 (95\% CI 0.99-1.18) [24], 1.11 (95\% CI $1.00-1.22)$ [25], 1.10 (95\% CI 1.01-1.20) [38] and 1.15 (95\% CI 1.03-1.29) [26] in favor of patients not receiving ESA. Figure 6 illustrates the shift of effect size in the cohort of studies published before 2002 (cutoff date for study inclusion for the first review) [22] and 2002-2005 (cutoff date for study inclusion for the second, updated review) [24].

Potential reasons for these observed changes can be found both at the level of the individual trials and at the level of the meta-analysis. Several characteristics of the clinical trials had changed between early and more recent studies, including study design, patient characteristics and ESA treatment schedules. For example, $\mathrm{Hb}$ 
Original studies

Kurz, 1997

Cascinu, 1994

Cazzola, 1995

Throuvalas, 2000

Dunphy, 1999

Dammacco, 2001

Del Mastro, 1997

Oberhoff, 1998

Thatcher, 1999a

Henry, 1995

Österborg, 1996b

Ten Bokkel, 1998

Littlewood, 2001

Abels, 1993

Coiffier, 2001

Case, 1993

Österborg, 2002

Thatcher, 1999b

Österborg, 1996a

Rose, 1994

Thompson, 2000

Subtotal $(95 \% \mathrm{Cl})$

New studies since 2002

Hedenus, 2002

Vadhan-Raj J\&

P-174 J\&J

Kotasek, 2003

Vansteenkiste Amgen

GOG-0191 J\&J

Chang, 2005

Savonije, 2004

Razzouk, 2004

EPO-GBR-7 J\& J

Witzig, 2005

Henke, 2003 Roche

Hedenus, 2003 Amgen

Leyland-Jones J\&J

Machtay, 2004

N93 004 FDA

INT-3 J\& J

INT-1 J\&J

Bamias, 2003

EPO-CAN-20 J\&J

EPO-CAN-15 J\& J

Smith, 2003

O'Shaughnessy, 2005

Subtotal $(95 \% \mathrm{Cl})$

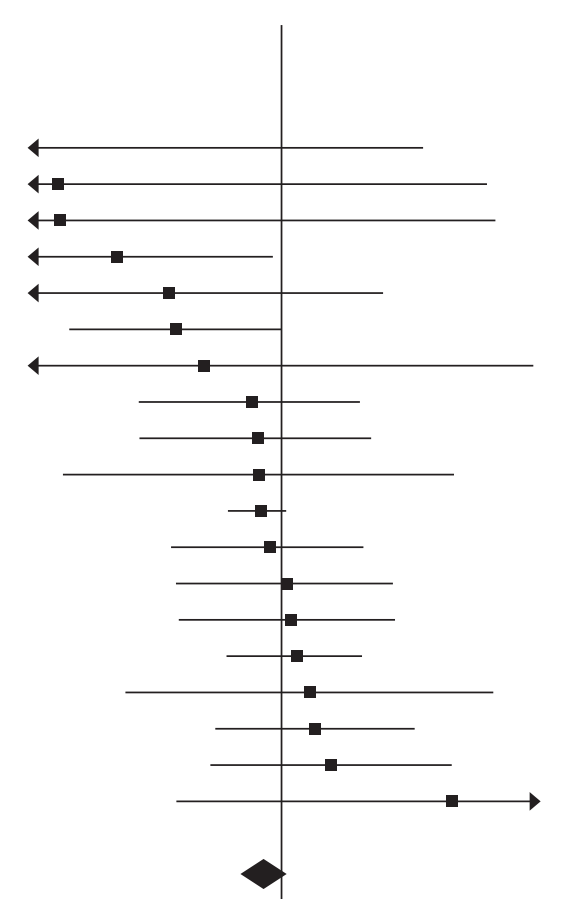

Studies before 2002

HR 0.84 (95\% Cl 0.69-1.02)

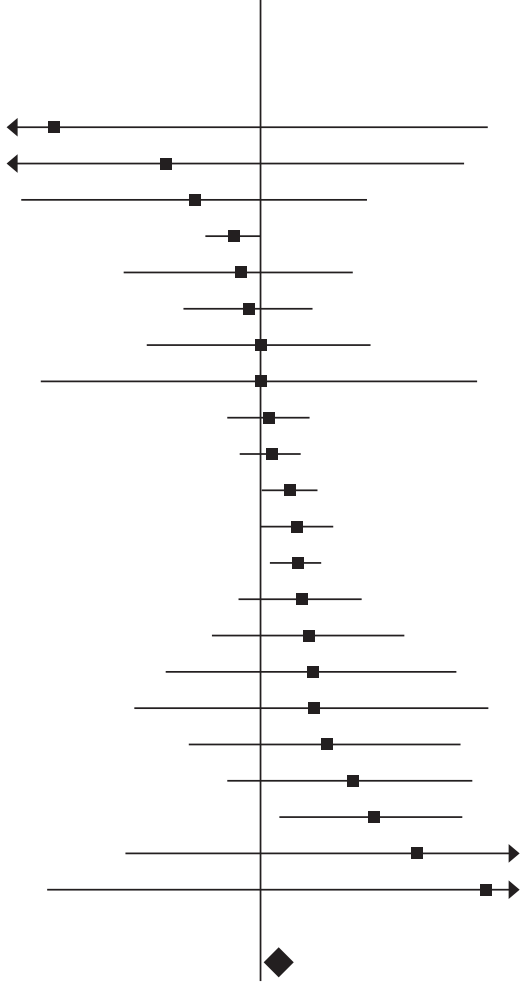

Studies after 2002

HR 1.16 (95\% CI 1.04-1.29

Fig. 6. Subgroup analysis of studies reporting mortality data published before and after the year 2002, data taken from Bohlius et al. [22] published in 2005 and Bohlius et al. [24] published in 2006. 
levels when ESAs had to be started and stopped were raised, and ESA dose as well as treatment duration was augmented. Moreover, studies included more patients with solid tumors and less often patients with hematological malignancies. At the same time, later studies reported more often an increased risk for death in ESA patients compared to controls. However, based on single RCTs and literature-based meta-analyses it was unclear whether detrimental effects observed were due to chance, bias, confounding or whether ESA patients are truly at a higher risk to die. In literature-based metaanalyses methods to disentangle the effects of patient and study level covariates are limited and will be outlined below.

Meta-regression can be used to explore the effect of study level characteristics on the result of a meta-analysis [59]. Study level characteristics refer to variables that apply to the entire population of a given study. For example whether or not the study was placebo controlled or designed to assess a specific outcome. Meta-regression can investigate the impact of study level variables; however, the analysis of co-variates at patient level is problematic [59]. These refer to characteristics of individual patients in a given trial, such as age, sex, tumor stage and tumor type or $\mathrm{Hb}$ level at randomization. These data are usually aggregated per study arm when reported in the literature. However, aggregated mean or median values do not represent the individual patient. For example, to examine the association between $\mathrm{Hb}$ levels at randomization, ESA treatment and risk for death, the $\mathrm{Hb}$ value and the survival outcome must be known for each patient. Published literature usually provides only the mean $\mathrm{Hb}$ level of the whole study group as well as aggregated survival estimates. Regression analyses based on aggregated patient characteristics represented as average values or percentages are prone to the ecological fallacy $[60,61]$. Thus, to explore the effect of risk factors at patient level, the use of IPD is strictly recommended [59].

Besides, timing of survival assessment may vary across studies with some studies reporting mortality during ESA treatment only and others only during longterm follow-up. This poses a problem if the death hazard changes over time. If ESA treatment increases mortality during administration but not thereafter the ability to analyze survival at different lengths of follow-up becomes crucial. In literature-based meta-analyses, authors have to rely on reported results, with absent or inconsistent reporting of survival. Survival may not have been reported at all, only during the study or for the last follow-up available. Particular strategies, e.g. conducting a separate analysis or combination of these different time points, may lead to bias such as potential over- or underestimation of the effects of ESAs on mortality.

Finally, bias at the meta-analysis level may have contributed to the optimistic early meta-analysis results, too. There is evidence that positive results are published earlier than results showing neutral or detrimental effects [62]. Thus, desirable results for survival when receiving ESAs may have been published earlier while neutral or even unfavorable results of ESA studies were potentially not reported or reported later. Of note, in a recently conducted IPD meta-analysis including both published and unpublished survival data, there was no evidence for a survival advantage in patients recruited early, i.e. before 2000 (HR 0.95, 95\% CI 0.60-1.30 for patients randomized between 1990 and 1994, and HR 0.96, 95\% CI 0.60-1.32, for patients randomized between 1995 and 1999) [63]. This underlines the observation that more beneficial survival data might have been published earlier than less beneficial results, which in turn may have led to a bias regarding the effect of ESAs on survival in the first literature-based meta-analysis [22]. Thus, literature-based meta-analyses are more prone to publication bias and delay of publication than IPD metaanalyses. Ideally, these limitations should be overcome by timely publication of all study results independent from the effect sizes achieved. In the meantime, metaanalyses of early studies should be judged with caution, and regular updates of literature-based meta-analyses are needed.

In contrast to literature-based meta-analysis, IPD enable researchers to access both published and unpublished data, harmonize outcome definitions and apply standardized analysis techniques across studies. In addition, time-to-event analyses based on IPD allow investigating subgroups of interest and to explore potential confounders and effect modifiers both at patient and study level [64]. Finally, IPD meta-analyses have larger power to find treatment interactions with co-variates at patient level [59].

To date, five meta-analyses on the effects of ESAs on survival were based on IPD $[30,39,63,65,66]$ (fig. 5, lower part). Four of the studies were conducted or funded by pharmaceutical companies manufacturing ESAs $[30,39,65,66]$ and one was conducted by an independent working group [63]. Two of the manufacturers' meta-analyses were restricted to specific erythropoiesisstimulating drugs such as epoetin $\beta[39,66]$ or darbepoetin $[30,65]$, which led to the omission of detrimental 
studies $[52,55]$ and reduced the statistical power of the meta-analyses. The meta-analysis on epoetin $\beta[39,66]$ was recently updated, including new analyses but no additional study data [67].

The independent IPD meta-analysis included 53 studies with 13,933 patients [63]. Access to IPD allowed differentiating study mortality, defined as treatment period plus 30-day follow-up, from overall survival, defined as last follow-up available. The risk for death during the study period was increased in ESA patients compared to controls: HR 1.17 (95\% CI 1.06-1.30). For overall survival, the detrimental effects of ESAs were smaller: HR 1.06 (95\% CI 1.00-1.12). Similar results were generated in the other IPD meta-analyses conducted [30,39]. These metaanalyses did not reach conventional levels of statistical significance which in part might be due to a lack of power because only selected drugs, i.e. epoetin $\beta$ or darbepoetin, were considered.

Another potential advantage of IPD meta-analyses is the ability to identify effect modifiers indicating whether certain subgroups of patients are either at increased or decreased risk to die when receiving ESAs compared to controls. The independent IPD meta-analysis conducted by Bohlius et al. [63] generated some evidence for such subgroups. ESA-treated patients with low hematocrit at baseline $(<23.5 \%)$ had an increased risk of death compared with other subgroups. A low hematocrit might be a marker for advanced cancer and increased susceptibility to the detrimental effects of ESAs. Patients with previous thromboembolic events being treated with ESAs were less likely to die when receiving ESAs. Hypothetically, prophylactic anticoagulation during cancer treatment in patients with previous thromboembolic events might have protected them against the thrombogenic effects of ESAs. Lastly, patients with increased frequency of ESA treatments had a reduced likelihood of death compared with others, and the association was confounded by other study characteristics. For other covariates such as $\mathrm{Hb}$ concentration at baseline, target $\mathrm{Hb}$ or planned ESA doses, there was no evidence for an interaction. Overall, it was not possible to identify with certainty a group of patients that is either at increased or decreased risk to die when receiving ESAs compared to other patients. Although these are disappointing findings, they illustrate that IPD meta-analyses can help to generate new hypotheses which then need to be tested in clinical trials.

There is an ongoing debate whether ESAs increase mortality in patients undergoing chemotherapy. From a clinical point of view, patients receiving concurrent che- motherapy may reach lower $\mathrm{Hb}$ levels under ESA treatment compared to patients not receiving chemotherapy. This may translate into a lower risk for lethal TVEs and impaired tumor control. When comparing the two most recent meta-analyses of IPD addressing this issue, both meta-analyses [30, 63] found an increased risk for onstudy mortality in cancer patients undergoing both chemotherapy and ESA treatment compared to controls (HR 1.11, 95\% CI 0.84-1.47, $\mathrm{n}=2,112$ [30], and HR 1.10, $95 \%$ CI 0.98-1.24, $\mathrm{n}=10,441$ [63]). In both meta-analyses the observed effect for on-study mortality was not statistically significant. Assuming a mortality rate of $10 \%$ during an average trial duration of 16 weeks in cancer patients receiving chemotherapy, the HR for on study mortality of 1.10 is equivalent to an absolute risk difference of $1 \%$. In order to detect this difference in a clinical study with an $\alpha$ level set at $5 \%$ and $\beta$ of $20 \%$, about 30,000 patients would be needed to reach sufficient statistical power to detect this difference. Thus, even current metaanalyses of IPD on 2,122 [30] and 10,441 [63] patients do not provide sufficient power to detect this small difference.

However, it is questionable whether restriction to a specific subgroup of interest is the most adequate approach to explore the effects of ESAs in cancer patients receiving chemotherapy. An alternative approach utilizing all available data is to compare different subgroups of patients, i.e. patients undergoing radiotherapy, radiochemotherapy, chemotherapy or no anticancer treatment when receiving ESAs, using an interaction test. Figure 7 shows the results of different treatment subgroups and the test for interaction [63]. Importantly, the test for interaction between subgroups was not statistically significant $(p=0.42)$. Thus, from a statistical point of view, the HR to die when receiving ESAs compared to controls did not differ between subgroups. Currently, an increased risk to die cannot be excluded in ESA patients undergoing chemotherapy compared to other subgroups receiving other anticancer interventions.

\section{Discussion}

From a methodological and clinical point of view, systematic reviews and meta-analyses have several advantages over single studies or narrative reviews [37] and can help to improve patient management. In the case of ESAs, literature-based meta-analyses convincingly helped to inform patients and caregivers about the beneficial effects of ESAs by reducing the RBCT risk. 


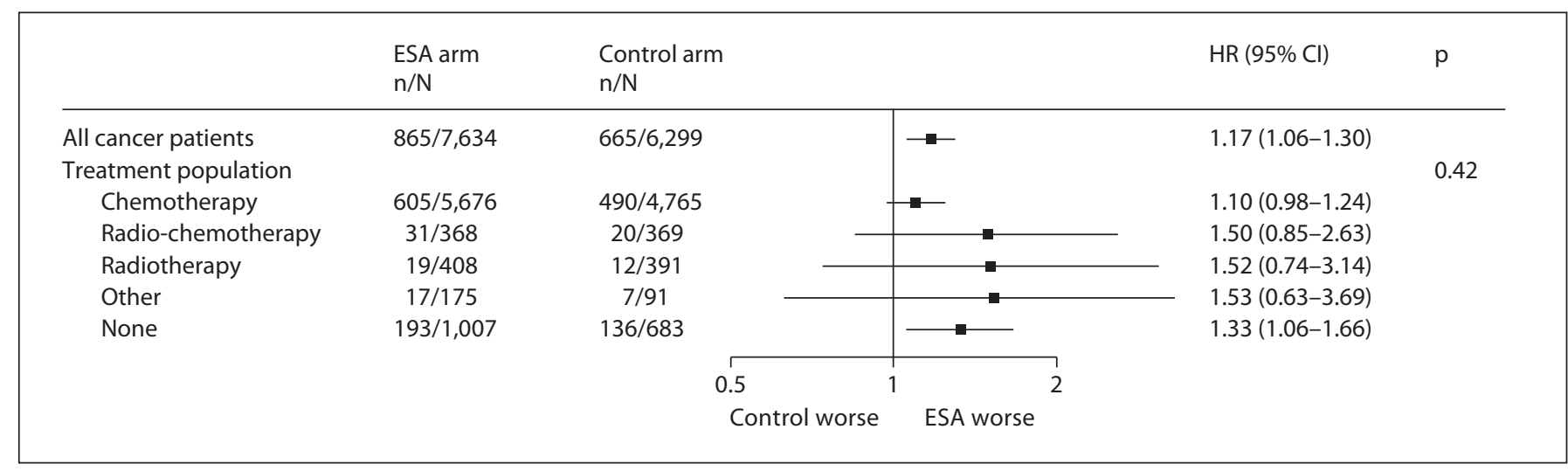

Fig. 7. Subgroup analysis of different treatment groups in the meta-analysis by Bohlius et al. [63]. The p value for interaction is based on Cox regression stratified by study. $\mathrm{n}=$ Number of deaths; $\mathrm{N}=$ number of patients.

Inclusion of unreported data helped to obtain a more conservative and realistic estimate of the expected treatment effect. Based on the large number of studies and patients included in the ESA meta-analyses, smaller risks associated with ESAs could be detected, which were not observed in single studies. For example, an increased risk for thromboembolic events could be identified based on the analysis of $>6,600$ patients from 35 trials [24].

Drawbacks of literature-based meta-analyses include inconsistent and incomplete reporting of outcomes across trials. Therefore, literature-based meta-analyses were not particularly suited to quantify the mortality risks associated with ESAs. In this situation, IPD metaanalyses helped to standardize and harmonize outcomes and analyses across trials. Nevertheless, even with a large-scale IPD meta-analysis it was not possible to identify with certainty patient groups that were at either increased or decreased risk to die when receiving ESAs [63].

Meta-analyses of IPD have some capacity to explore causal pathways of treatment actions. However, these are in principle of observational nature only and help to generate hypotheses on the causal pathways which then need to be tested in subsequent clinical trials. The main limitation of these meta-analyses are barriers to the access of clinical trial data and resource constraints both at the side of the meta-analysis team and the original investigator. In the case of ESAs, a large collaboration between manufacturers, clinical trialists and a meta-analysis team was established, which enabled to conduct an IPD metaanalysis on the effects of ESAs in cancer patients [63].
Given that IPD accumulated in meta-analyses offer a rich source for further analyses, in certain situations these efforts are worthwhile and should be encouraged. Sufficient independent funding and formal agreements on data sharing with the principal investigators of the respective studies constitute key factors for any IPD metaanalysis.

\section{Considerations for Patient Treatment}

The findings of several meta-analyses on ESAs in cancer patients demonstrate that ESAs reduce the risk for RBCT and increase the risk for TVEs and mortality. There is an ongoing debate whether or not ESAs increase mortality in cancer patients receiving chemotherapy as well. However, the currently available data are insufficient to exclude an increased risk for death in cancer patients undergoing chemotherapy and receiving ESAs. In clinical practice, the increased risks of death and TVEs should be balanced against the benefits of treatment with ESAs, taking into account each patient's clinical circumstances and preferences.

\section{Considerations for Further Systematic Reviews and Meta-Analyses}

Further literature-based systematic reviews and metaanalyses should focus on adjacent topics such as iron supplementation with ESAs and different ESA management schedules. Given that ESAs are widely used in cancer pa- 
tients and considering the possible detrimental effects on important clinical outcomes, such as risk for thromboembolic events and death, a better understanding of the potential benefits of ESAs in cancer patients is urgently needed. Currently, there is no consensus whether ESAs improve QoL in cancer patients. An IPD meta-analysis on the effects of ESAs on QoL in cancer patients would provide a unique opportunity to gather appropriate data from a large number of RCTs to define the potential impact of ESAs on QoL in cancer patients and to better define the risk-benefit ratio of ESAs in cancer patients. Definite results concerning the risks and benefits would help patients, physicians, guideline committees and health authorities to make informed decisions about the use of ESAs.

\section{References}

$>_{1}$ Knight K, Wade S, Balducci L: Prevalence and outcomes of anemia in cancer: a systematic review of the literature. Am J Med 2004; 116:11S-26S.

-2 Ludwig H, Van Belle S, Barrett-Lee P, Birgegard G, Bokemeyer C, Gascon P, Kosmidis P, Krzakowski M, Nortier J, Olmi P, Schneider M, Schrijvers D: The European Cancer Anaemia Survey (ECAS): a large, multinational, prospective survey defining the prevalence, incidence, and treatment of anaemia in cancer patients. Eur J Cancer 2004;40: 2293-2306.

3 Groopman JE, Itri LM: Chemotherapy-induced anemia in adults: incidence and treatment. J Natl Cancer Inst 1999;91:1616-1634.

4 Ludwig H, Strasser K: Symptomatology of anemia. Semin Oncol 2001;28:7-14

5 Caro JJ, Salas M, Ward A, Goss G: Anemia as an independent prognostic factor for survival in patients with cancer: a systemic, quantitative review. Cancer 2001;91:2214-2221.

6 Goodnough LT: Risks of blood transfusion. Anesthesiol Clin North America 2005;23: 241-252.

7 Storring PL, Tiplady RJ, Gaines Das RE, Stenning BE, Lamikanra A, Rafferty B, Lee J: Epoetin alfa and beta differ in their erythropoietin isoform compositions and biological properties. Br J Haematol 1998;100:79-89.

8 Glaspy J, Vadhan-Raj S, Patel R, Bosserman L, Hu E, Lloyd RE, Boccia RV, Tomita D, Rossi G: Randomized comparison of every-2week darbepoetin alfa and weekly epoetin alfa for the treatment of chemotherapy-induced anemia: the 20030125 Study Group Trial. J Clin Oncol 2006;24:2290-2297.

9 Continuing Reassessment of the Risks of Erythropoiesis-Stimulating Agents (ESAs) Administered for the Treatment of Anemia Associated with Cancer Chemotherapy: Oncology Drugs Advisory Committee, 2007. http://www.fda.gov/ohrms/dockets/ac/07/ briefing/2007-4301b2-02-FDA.pdf.

10 Dmoszynska A, Kloczko J, Rokicka M, Hellmann A, Spicka I, Eid JE: A dose exploration, phase I/II study of administration of continuous erythropoietin receptor activator once every 3 weeks in anemic patients with multiple myeloma receiving chemotherapy. Haematologica 2007;92:493-501.
1 Osterborg A, Steegmann JL, Hellmann A, Couban S, Mayer J, Eid JE: Phase II study of three dose levels of continuous erythropoietin receptor activator (C.E.R.A.) in anaemic patients with aggressive non-Hodgkin's lymphoma receiving combination chemotherapy. Br J Haematol 2007;136:736-744.

12 Krzakowski M: Epoetin delta: efficacy in the treatment of anaemia in cancer patients receiving chemotherapy. Clin Oncol (R Coll Radiol) 2008;20:705-713.

13 Jelkmann W, Bohlius J, Hallek M, Sytkowski AJ: The erythropoietin receptor in normal and cancer tissues. Crit Rev Oncol Hematol 2008;67:39-61.

14 Quirt I, Micucci S, Moran LA, Pater J, Browman G: Erythropoietin in the management of patients with nonhematologic cancer receiving chemotherapy. Systemic Treatment Program Committee. Cancer Prev Control 1997;1:241-248.

15 Marsh WA, Rascati KL: Meta-analyses of the effectiveness of erythropoietin for end-stage renal disease and cancer. Clin Ther 1999;21: 1443-1455.

16 Ross SD, Allen IE, Probst CA, Sercus B, Crean SM, Ranganathan G: Efficacy and safety of erythropoiesis-stimulating proteins in myelodysplastic syndrome: a systematic review and meta-analysis. Oncologist 2007;12:1264-1273.

17 Mundle S, Lefebvre P, Vekeman F, Duh MS, Rastogi R, Moyo V: An assessment of erythroid response to epoetin alpha as a single agent versus in combination with granulocyte- or granulocyte-macrophage-colonystimulating factor in myelodysplastic syndromes using a meta-analysis approach. Cancer 2009; 115:706-715.

18 Lambin P, Ramaekers BL, van Mastrigt GA, Van den Ende P, de Jong J, De Ruysscher DK, Pijls-Johannesma M: Erythropoietin as an adjuvant treatment with (chemo) radiation therapy for head and neck cancer. Cochrane Database Syst Rev 2009;3:CD006158.

19 Cella D, Kallich J, McDermott A, Xu X: The longitudinal relationship of hemoglobin, fatigue and quality of life in anemic cancer patients: results from five randomized clinical trials. Ann Oncol 2004;15:979-986.
20 Minton O, Richardson A, Sharpe M, Hotopf $\mathrm{M}$, Stone P: A systematic review and metaanalysis of the pharmacological treatment of cancer-related fatigue. J Natl Cancer Inst 2008;100:1155-1166.

21 Seidenfeld J, Piper M, Flamm C, Hasselblad V, Armitage JO, Bennett CL, Gordon MS, Lichtin AE, Wade JL 3rd, Woolf S, Aronson $\mathrm{N}$ : Epoetin treatment of anemia associated with cancer therapy: a systematic review and meta-analysis of controlled clinical trials. J Natl Cancer Inst 2001;93:1204-1214.

22 Bohlius J, Langensiepen S, Schwarzer G, Seidenfeld J, Piper M, Bennett C, Engert A: Recombinant human erythropoietin and overall survival in cancer patients: results of a comprehensive meta-analysis. J Natl Cancer Inst 2005;97:489-498.

23 Wilson J, Yao GL, Raftery J, Bohlius J, Brunskill S, Sandercock J, Bayliss S, Moss P, Stanworth S, Hyde C: A systematic review and economic evaluation of epoetin alpha, epoetin beta and darbepoetin alpha in anaemia associated with cancer, especially that attributable to cancer treatment. Health Technol Assess 2007;11:1-220.

24 Bohlius J, Wilson J, Seidenfeld J, Piper M, Schwarzer G, Sandercock J, Trelle S, Weingart O, Bayliss S, Djulbegovic B, Bennett CL, Langensiepen S, Hyde C, Engert A: Recombinant human erythropoietins and cancer patients: updated meta-analysis of 57 studies including 9353 patients. J Natl Cancer Inst 2006;98:708-714.

25 Seidenfeld J, Piper M, Bohlius J, Weingart O, Trelle S, Engert A, Skoetz N, Schwarzer G, Wilson J, Brunskill S, Hyde C, Bonnell C, Ziegler KM, Aronson N: Comparative effectiveness of epoetin and darbepoetin for managing anemia in patients undergoing cancer treatment. Rockville, Agency for Healthcare Research and Quality, 2006, www.effectivehealthcare.ahrq.gov/reports/ final.cfm.

26 Tonelli M, Hemmelgarn B, Reiman T, Manns B, Reaume MN, Lloyd A, Wiebe N, Klarenbach S: Benefits and harms of erythropoiesis-stimulating agents for anemia related to cancer: a meta-analysis. CMAJ 2009; 180: E62-E71. 
$\longrightarrow 27$ Ross SD, Allen IE, Henry DH, Seaman C, Sercus B, Goodnough LT: Clinical benefits and risks associated with epoetin and darbepoetin in patients with chemotherapy-induced anemia: a systematic review of the literature. Clin Ther 2006;28:801-831.

$\checkmark 28$ Couture F, Turner AR, Melosky B, Xiu L, Plante RK, Lau CY, Quirt I: Prior red blood cell transfusions in cancer patients increase the risk of subsequent transfusions with or without recombinant human erythropoietin management. Oncologist 2005;10:63-71.

-29 Clark O, Adams JR, Bennett CL, Djulbegovic B: Erythropoietin, uncertainty principle and cancer related anaemia. BMC Cancer 2002;2:23.

- 30 Ludwig H, Crawford J, Osterborg A, Vansteenkiste J, Henry DH, Fleishman A, Bridges K, Glaspy JA: Pooled analysis of individual patient-level data from all randomized, double-blind, placebo-controlled trials of darbepoetin alfa in the treatment of patients with chemotherapy-induced anemia. J Clin Oncol 2009;27:2838-2347.

31 Sackett DL, Deeks JJ, Altman DG: Down with odds ratios! Evidence-Based Medicine 1996;1:164-166.

32 Bohlius J, Wilson J, Seidenfeld J, Piper M, Schwarzer G, Sandercock J, Trelle S, Weingart O, Bayliss S, Brunskill S, Djulbegovic B, Benett CL, Langensiepen S, Hyde C, Engert E: Erythropoietin or darbepoetin for patients with cancer. Cochrane Database Syst Rev 2006;3:CD003407.

-33 Harbord RM, Egger M, Sterne JA: A modified test for small-study effects in meta-analyses of controlled trials with binary endpoints. Stat Med 2006;25:3443-3457.

34 Duval S: The Trim and Fill Method. Publication Bias in Meta-Analysis - Prevention, Assessment and Adjustments. Chichester, Wiley, 2005, pp 127-144.

- 35 Carpenter JR, Schwarzer G, Ruecker G, Kuenstler R: Empirical evaluation showed that the Copas selection model provided a useful summary in $80 \%$ of meta-analyses. J Clin Epidemiol 2009;62:624-631.

- 36 Stohlawetz PJ, Dzirlo L, Hergovich N, Lackner E, Mensik C, Eichler HG, Kabrna E, Geissler K, Jilma B: Effects of erythropoietin on platelet reactivity and thrombopoiesis in humans. Blood 2000;95:2983-2989.

-37 Egger M, Smith GD: Meta-analysis - potentials and promise. BMJ 1997;315:1371-1374.

38 Bennett CL, Silver SM, Djulbegovic B, Samaras AT, Blau CA, Gleason KJ, Barnato SE, Elverman KM, Courtney DM, Mckoy JM, Edwards BJ, Tigue CC, Raisch DW, Yarnold PR, Dorr DA, Kuzel TM, Tallman MS, Trifilio SM, West DP, Lai SY, Henke M: Venous thromboembolism and mortality associated with recombinant erythropoietin and darbepoetin administration for the treatment of cancer-associated anemia. JAMA 2008;299: 914-924.
9 Aapro M, Scherhag A, Burger HU: Effect of treatment with epoetin-beta on survival, tumour progression and thromboembolic events in patients with cancer: an updated meta-analysis of 12 randomised controlled studies including 2,301 patients. Br J Cancer 2008;99:14-22.

40 Glaspy J, Crawford J, Vansteenkiste J, Henry D, Rao S, Bowers P, Berlin JA, Tomita D, Bridges K, Ludwig H: Erythropoiesis-stimulating agents in oncology: a study-level metaanalysis of survival and other safety outcomes. Br J Cancer 2010;102:301-315.

41 Aapro M, Leonard RC, Barnadas A, Marangolo M, Untch M, Malamos N, Mayordomo J, Reichert D, Pedrini JL, Ukarma L, Scherhag A, Burger HU: Effect of once-weekly epoetin beta on survival in patients with metastatic breast cancer receiving anthracycline- and/or taxane-based chemotherapy: results of the Breast Cancer-Anemia and the Value of Erythropoietin (BRAVE) study. J Clin Oncol 2008;26:592-598.

-42 Pirker R, Ramlau RA, Schuette W, Zatloukal P, Ferreira I, Lillie T, Vansteenkiste JF: Safety and efficacy of darbepoetin alpha in previously untreated extensive-stage small-cell lung cancer treated with platinum plus etoposide. J Clin Oncol 2008;26:2342-2349.

43 Kirkham JJ, Dwan KM, Altman DG, Gamble C, Dodd S, Smyth R, Williamson PR: The impact of outcome reporting bias in randomised controlled trials on a cohort of systematic reviews. BMJ 2010;340:c365.

44 Vaupel P, Mayer A: Hypoxia and anemia: effects on tumor biology and treatment resistance. Transfus Clin Biol 2005;12:5-10.

45 Hockel M, Knoop C, Schlenger K, Vorndran B, Baussmann E, Mitze M, Knapstein PG, Vaupel P: Intratumoral $\mathrm{pO}_{2}$ predicts survival in advanced cancer of the uterine cervix. Radiother Oncol 1993;26:45-50.

46 Kelleher DK, Mattheinsen U, Thews O, Vaupel P: Blood flow, oxygenation, and bioenergetic status of tumors after erythropoietin treatment in normal and anemic rats. Cancer Res 1996;56:4728-4734.

47 Thews O, Koenig R, Kelleher DK, Kutzner J, Vaupel P: Enhanced radiosensitivity in experimental tumours following erythropoietin treatment of chemotherapy-induced anaemia. Br J Cancer 1998;78:752-756.

48 Silver DF, Piver MS: Effects of recombinant human erythropoietin on the antitumor effect of cisplatin in SCID mice bearing human ovarian cancer: a possible oxygen effect. Gynecol Oncol 1999;73:280-284.

49 Thews O, Kelleher DK, Vaupel P: Erythropoietin restores the anemia-induced reduction in cyclophosphamide cytotoxicity in rat tumors. Cancer Res 2001;61:1358-1361.

50 Stuben G, Pottgen C, Knuhmann K, Schmidt K, Stuschke M, Thews O, Vaupel P: Erythropoietin restores the anemia-induced reduction in radiosensitivity of experimental human tumors in nude mice. Int J Radiat Oncol Biol Phys 2003;55:1358-1362.
51 Littlewood TJ, Bajetta E, Nortier JW, Vercammen E, Rapoport B, Epoetin Alfa Study Group: Effects of epoetin alfa on hematologic parameters and quality of life in cancer patients receiving nonplatinum chemotherapy: results of a randomized, double-blind, placebo-controlled trial. J Clin Oncol 2001;19: 2865-2874.

52 Henke M, Laszig R, Rübe C, Schäfer U, Haase KD, Schilcher B, Mose S, Beer KT, Burger U, Dougherty C, Frommhold H: Erythropoietin to treat head and neck cancer patients with anaemia undergoing radiotherapy: randomised, double-blind, placebo-controlled trial. Lancet 2003;362:1255-1260.

53 Overgaard J Sr, Hoff CM, Hansen HS, Specht L, Overgaard M, Grau C, Andersen E, Johansen J, Andersen LJ, Evensen JF, Danish Head and Neck Cancer Group (DAHANCA): Randomized study of darbepoetin alfa as modifier of radiotherapy in patients with primary squamous cell carcinoma of the head and neck (HNSCC): final outcome of the DAHANCA 10 trial (abstract 6007). 2009 ASCO Annual Meeting. http://www.asco.org/ ASCOv2/Meetings/Abstracts?\&vmview= abst_detail_view\&confID $=65 \&$ abstract ID $=35348$.

54 Leyland-Jones B: Breast cancer trial with erythropoietin terminated unexpectedly. Lancet Oncol 2003;4:459-460.

55 Leyland-Jones B, Semiglazov V, Pawlicki M, Pienkowski T, Tjulandin S, Manikhas G, Makhson A, Roth A, Dodwell D, Baselga J, Biakhov M, Valuckas K, Voznyi E, Liu X, Vercammen E: Maintaining normal hemoglobin levels with epoetin alfa in mainly nonanemic patients with metastatic breast cancer receiving first-line chemotherapy: a survival study. J Clin Oncol 2005;23:58655868.

56 Smith RE Jr, Aapro MS, Ludwig H, Pintér T, Smakal M, Ciuleanu TE, Chen L, Lillie T, Glaspy JA: Darbepoetin alpha for the treatment of anemia in patients with active cancer not receiving chemotherapy or radiotherapy: results of a phase III, multicenter, randomized, double-blind, placebo-controlled study. J Clin Oncol 2008;26:1040-1050.

57 Luksenburg H, Weir A, Wager R: Safety concerns associated with Aranesp (darbepoetin alfa) Amgen, Inc. and Procrit (epoetin alfa) Ortho Biotech, L.P., for the treatment of anemia associated with cancer chemotherapy. ODAC Meeting, 2004. http://www.fda.gov/ ohrms/dockets/ac/04/briefing/4037b2_04. pdf.

58 FDA Briefing Document. Oncologic Drug Advisory Committee, 2008. http://www.fda. gov/ohrms/dockets/ac/08/briefing/20084345b2-01-FDA.pdf.

59 Schmid CH, Stark PC, Berlin JA, Landais P, Lau J: Meta-regression detected associations between heterogeneous treatment effects and study-level, but not patient-level, factors. J Clin Epidemiol 2004;57:683-697. 
60 Greenland S: Quantitative methods in the review of epidemiologic literature. Epidemiol Rev 1987;9:1-30.

-61 Berlin JA, Santanna J, Schmid CH, Szczech LA, Feldman HI: Individual patient- versus group-level data meta-regressions for the investigation of treatment effect modifiers: ecological bias rears its ugly head. Stat Med 2002;21:371-387.

62 Stern JM, Simes RJ: Publication bias: evidence of delayed publication in a cohort study of clinical research projects. BMJ 1997; 315:640-645.
63 Bohlius J, Schmidlin K, Brillant C, Schwarzer G, Trelle S, Seidenfeld J, Zwahlen M, Clarke M, Weingart O, Kluge S, Piper M, Rades D, Steensma DP, Djulbegovic B, Fey MF, Ray-Coquard I, Machtay M, Moebus V, Thomas G, Untch M, Schumacher M, Egger $M$, Engert A: Recombinant human erythropoiesis-stimulating agents and mortality in patients with cancer: a meta-analysis of randomised trials. Lancet 2009;373:1532-1542.

64 Simmonds MC, Higgins JP: Covariate heterogeneity in meta-analysis: criteria for deciding between meta-regression and individual patient data. Stat Med 2007;26: 2982-2999.

- 65 Hedenus M, Vansteenkiste J, Kotasek D, Austin M, Amado RG: Darbepoetin alfa for the treatment of chemotherapy-induced anemia: disease progression and survival analysis from four randomized, doubleblind, placebo-controlled trials. J Clin Oncol 2005;23:6941-6948.
66 Aapro M, Coiffier B, Dunst J, Osterborg A, Burger HU: Effect of treatment with epoetin beta on short-term tumour progression and survival in anaemic patients with cancer: a meta-analysis. Br J Cancer 2006;95:14671473.

67 Aapro M, Osterwalder B, Scherhag A, Burger $\mathrm{HU}$ : Epoetin-beta treatment in patients with cancer chemotherapy-induced anaemia: the impact of initial haemoglobin and target haemoglobin levels on survival, tumour progression and thromboembolic events. $\mathrm{Br} \mathrm{J}$ Cancer 2009;101:1961-1971. 